\title{
A GESTÃO ESCOLAR E SUA IMPORTÂNCIA PARA A ATUAÇÃO DA ESCOLA: CONSIDERAÇÕES TEÓRICAS
}

\author{
SCHOOL MANAGEMENT AND ITS IMPORTANCE FOR \\ SCHOOL PERFORMANCE: THEORETICAL CONSIDERATIONS
}

\author{
Marta da Cunha Santos ${ }^{1}$ e Noemi Boer ${ }^{2}$
}

\section{RESUMO}

Este estudo consiste numa reflexão sobre a importância da gestão escolar articulada à gestão educacional, às políticas internacionais e suas relações de interdependência. Considera-se que os conceitos de gestão educacional e escolar são de fundamental importância para entendermos as inter-relações que perpassam o contexto escolar. No que se refere à gestão educacional destaca-se sua importância na organização dos sistemas de ensino e como alicerce basilar da gestão escolar. No que tange à gestão escolar, enfatiza-se a sua contribuição na organização, mobilização e articulação dos diferentes setores da escola a fim de pôr em prática a sua proposta pedagógica e desenvolver um processo educacional de qualidade. O objetivo que se propõe neste estudo é o de compreender a importância da gestão escolar para a atuação da escola. Para tanto, foi desenvolvida uma pesquisa bibliográfica, alicerçada no método qualitativo, utilizando-se de autores de referência.

Palavras-chave: Gestão Educacional, Organização, Contexto escolar.

\section{ABSTRACT}

This study consists of a reflection on the importance of school management linked to educational management, international policies and their interdependent relationships. It is considered that the concepts of educational and school management are of fundamental importance to understand the interrelations that permeate the school context. With regard to educational management, its importance in the organization of teaching systems and as a basic foundation of school management stands out. With regard to school management, its contribution to the organization, mobilization and articulation of the different sectors of the school is emphasized in order to put into practice its pedagogical proposal and develop a quality educational process. The objective proposed in this study is to understand the importance of school management for the school's performance. For that, a bibliographic research was developed, based on the qualitative method, using reference authors.

Keywords: educational management, organization, school context.

1 Acadêmica do Curso de Mestrado em Ensino de Humanidades e Linguagens - MEHL - Universidade Franciscana - UFN. Especialista em Educação Infantil - UNIFRA. Especialista em Alfabetização em anos iniciais - UNIFRA. Especialista em Gestão de Instituições de Ensino - UNINTER. E-mail: cunhamcs@yahoo.com.br

2 Orientadora. Prof ${ }^{a}$. Dr ${ }^{\mathrm{a}}$. do Curso de Pedagogia e do Mestrado em Ensino de Humanidades e Linguagens, MEHL Universidade Franciscana - UFN. E-mail: noemiboer@gmail.com 


\section{INTRODUÇÃO}

As escolas são instituições que têm como objetivo a educação, o ensino e a aprendizagem dos alunos em relação aos conhecimentos, procedimentos, valores, tarefas que se cumprem pelas atividades pedagógicas e curriculares ao longo da vida. Os meios e condições de consecução desses objetivos, são assegurados pelas formas de organização da gestão educacional e gestão escolar.

Entretanto, não se pode falar em gestão escolar sem considerar a sua articulação de dependência à gestão educacional, e esta, sem orientação das políticas internacionais. Sabe-se o que as políticas internacionais têm interferido e influenciado o contexto educacional no Brasil ao longo dos anos, a partir da perspectiva política de governo e cultura da sua época.

As políticas educacionais não são neutras, são portadoras de intencionalidade, ideias, valores e atitudes que influenciam a gestão educacional, assim como a gestão escolar e suas práticas operacionais no contexto de suas relações. Segundo Akkari (2011), pode-se inferir que uma política é um conjunto de decisões tomadas antecipadamente para indicar orientações da sociedade em relação à escola.

Segundo Sander (2009), os processos de construção e reconstrução de concepções e práticas de gestão educacional revelam que o campo educacional brasileiro continua sendo hoje, como foi no passado, uma disputa de interesses em que diferentes atores tratam de impor suas opções político-pedagógicas, suas categorias de percepção e interpretação.

Neste contexto, verifica-se que gestão educacional de país se constitui como um amplo processo, que sofre influência de diferentes atores e contextos institucionais marcadamente influenciados por marcos regulatórios, fruto de orientações, compromissos e perspectivas, em escala nacional e mundial, que refletem necessidades sociais de sua época.

A gestão educacional se constitui uma área de fundamental importância da educação, uma vez que por meio dela se possibilita uma visão ampla (macro) e contextual ligadas a gestão dos sistemas de ensino na educação básica e ensino superior, e a partir daí oferece diretrizes para uma abordagem mais específica e direta (micro) no que se refere à escola.

\footnotetext{
Ressalta-se que a gestão educacional, em caráter amplo e abrangente do sistema de ensino, e a gestão escolar, referente à escola, constituem -se em área estrutural de ação na determinação da dinâmica da qualidade do ensino. Isso porque é pela gestão que se estabelece unidade, direcionamento, ímpeto, consistência, coerência à ação educacional, a partir do paradigma, ideário e estratégias adotadas para tanto. Porém é necessário ter em mente que é uma área -meio e não um fim em si mesma (LUCK, 2007, p. 15).
}

A partir do que preconiza a gestão educacional, pauta-se a forma de organização e condução da gestão escolar. Através desta, é que se efetiva a qualidade de ensino da escola É imperativo que escolas disponham de meios organizacionais e estratégias, organizadas a partir da gestão escolar para alcançar seus objetivos. 
As escolas são organizações educativas que têm tarefas sociais e éticas peculiares com um caráter profundamente democrático. Para atingir seus objetivos sociopolíticos, precisam dispor de meios operacionais, isto é, criar e desenvolver uma estrutura organizacional (setores, cargos, atribuições e normas), uma tecnologia, uma cultura organizacional, processos de gestão e tomada de decisões, assim como a análise dos resultados que contribuem para o processo formativo e para o aperfeiçoamento da gestão (LIBÂNEO, 2018, p. 16).

O estudo proposto é importante para entendermos as inter-relações que perpassam o contexto educacional para que possamos compreender o seu papel para a ação educativa na escola. No que se refere à gestão educacional, destaca-se a sua importância pelas contribuições como alicerce basilar a nortear, através de normas e diretrizes, a gestão escolar.

Sabe-se que a educação escolar possui a tarefa de promover a aprendizagem e apropriação de saberes através de suas práticas de ensino, procedimentos e valores por parte dos alunos, por meio da prática docente e pela organização e gestão da escola.

É importante destacar, que a organização da escola, do ponto de vista da gestão escolar, não pode ser vista apenas sob o aspecto administrativo. Seu contexto é abrangente, e cabe considerá-la sobretudo como espaço social, em que a relação entre os sujeitos e o contexto socioculturais são determinantes para o desenvolvimento da sua prática educativa.

As escolas existem para promover o desenvolvimento das potencialidades físicas, cognitivas e afetivas dos alunos por meio da aprendizagem de saberes e modos de ação, para que se transformem em cidadãos participativos na sociedade em que vivem. Seu objetivo primordial, portanto, é o ensino e a aprendizagem, que se cumpre pelas atividades pedagógicas, curriculares e docentes, estas, por sua vez, viabilizadas pelas formas de organização escolar e de gestão (LIBÂNEO, 2007, p. 155).

Neste artigo, primeiramente se faz uma contextualização da gestão educacional e a sua relação com as políticas internacionais. Posteriormente, se aborda a gestão escolar, destacando a sua relevância para a organização e execução da ação pedagógica da escola, tendo presente que “[...] as escolas visam à formação científica e cultural dos alunos buscando prepará-los para a vida profissional, cultural e cidadã e, para isso, necessitam de procedimentos e meios organizacionais através da gestão para alcançar seus objetivos" (LIBÂNEO, 2018, p. 268)

Espera-se com este trabalho, contribuir para demonstrar o papel relevante que a gestão escolar desempenha frente à condução de ações organizadas e orientadas para execução da efetivação da proposta pedagógica da escola, direcionamento da ação docente e a busca permanente de resultados educacionais positivos, tendo como foco a aprendizagem e a formação do aluno.

Nesse viés, propõe-se discutir a necessidade de a escola possuir uma gestão escolar organizada, a fim de criar e assegurar condições organizacionais, operacionais e pedagógicas para que possa viabilizar o bom desempenho do aluno, da prática pedagógica, mobilização e a articulação dos diferentes setores da escola. Com isso, garantir um processo educacional de qualidade. 
A natureza desta pesquisa é qualitativa e os fenômenos sociais são interpretados à luz do seu contexto, e das interferências que o atravessam. Isso reforça o que Michel (2015, p. 42) diz, ao afirmar que o "pesquisador participa, compreende e interpreta" quando se trata de uma pesquisa qualitativa". Para tanto, utilizou-se o método de revisão bibliográfica, partindo dos conceitos de gestão educacional e gestão escolar para elucidar a temática proposta, à luz de autores de referência como Akkari, Sander, Libâneo, Luck, entre outros.

\title{
GESTÃO EDUCACIONAL E O CONTEXTO DA EDUCAÇÃO NO BRASIL
}

As discussões sobre gestão educacional e gestão escolar tem sido objeto de vários estudos e debates no cenário nacional e internacional. No contexto da educação brasileira, tem se dado muita atenção à gestão, que supera o enfoque limitado de administração, a partir do entendimento que os problemas educacionais são complexos, em vista que demandam uma visão global e abrangente, com ação colaborativa e articulada.

A esse respeito, a gestão educacional

\begin{abstract}
[...] corresponde à área de atuação responsável por estabelecer o direcionamento e a mobilização capazes de sustentar e dinamizar o modo de ser e de fazer os sistemas de ensino e das escolas, para realizar ações conjuntas, associadas e articuladas, visando objetivo comum da qualidade do ensino e seus resultados (LUCK, 2006, p. 25).
\end{abstract}

Não se pode falar em gestão educacional e gestão escolar, sem falar de políticas internacionais, sabe-se o quanto as políticas internacionais influenciaram e influenciam o sistema educacional no Brasil, assim como em outros países. A internacionalização das políticas educacionais, bem como as relações dinâmicas entre elas, reflete-se no cenário educacional nacional e acarretaram mudanças significativas e desdobramentos em diferentes esferas educacionais

O processo de internacionalização das políticas educacionais gerou novas formas de regulação das políticas nacionais. Esse processo pode ser identificado, por meio de aspectos comuns, como a descentralização, a privatização, orçamento e a prática docente.

A partir da globalização, a influência das organizações internacionais, sobre o contexto educacional brasileiro é muito expressivo. Conforme destaca, Akkari (2011), entre estas organizações podemos citar sobretudo, a Organização das Nações Unidas (ONU), a Organização das Nações Unidas para a Educação, Ciência e Cultura (UNESCO) e o Fundo das Nações Unidas para Infância (UNICEF), estas são as agências reguladoras especializadas, que se preocupam com os caminhos de educação a nível mundial e a abrangência de suas ações, têm o objetivo de amenizar as desigualdades e o acesso à educação.

Como também, podemos considerar o Banco Mundial, a Organização Mundial do Comércio (OMC) e Organização para a cooperação e desenvolvimento econômico (OCDE), organismos econômicos, que financiam e impactam de diferentes formas o sistema educacional. Além das contribuições 
a nível de diretrizes e financiamento, estes organismos internacionais, viabilizam um alinhamento de ações a nível nacional ao contexto internacional. E trouxeram desafios políticos quanto a sua implementação de operacionalização, considerando a diversidades da realidade social brasileira aos demais países.

Segundo Akkari (2011), esclarece o conceito de política educacional, como sendo o conjunto de decisões tomadas para indicar, as expectativas e orientações da sociedade em relação à escola e o ensino, visando assegurar e adequar as necessidades sociais de educação e os serviços prestados pelos sistemas educacionais.

As políticas estão intimamente relacionadas ao sistema de governo, a um modelo de estado, ou seja, as políticas refletem um modelo de governo, que por sua vez reflete num modelo de gestão educacional.

Cabe considerar, que, gestão educacional de país um é um processo amplo, que recebe influências de diferentes atores e contextos institucionais marcadamente influenciados por marcos regulatórios fruto de orientações, compromissos e perspectivas, em escala nacional e mundial.

Percebe-se que no Brasil, as concepções de gestão da educação refletiram uma orientação elaborada a partir da perspectiva política e cultural do país no contexto de suas relações de interdependência internacional. “Ou seja, as concepções de gestão da educação refletem distintas filosofias sociais elaboradas a partir de diferentes perspectivas políticas e culturais nacionais historicamente situadas no contexto das relações de interdependência internacional” (SANDER, 2009, p. 70).

No Brasil, a organização da gestão educacional, é baseado na organização dos sistemas de ensino e na interrelação das esferas federais, estaduais e municipais, das formas de articulação entre as mesmas, de normas que a determinam, executam e deliberam a oferta da educação pelo setor público e privado.

A gestão educacional diz respeito ao macro dos sistemas de ensino e possibilita articular ações integradas ente a União, Estados e Municípios, possibilitando articular ações estratégicas, visando otimizar resultados na área da educação.

Daí por que a importância da gestão educacional, na determinação desse novo destino, uma vez que, a partir de seu enfoque de visão de conjunto e orientação estratégica de futuro, tendo por base a mobilização de pessoas articuladas em equipe, permite articular ações e estabelecer a devida mobilização para maximizar resultados (LUCK, 2007, p. 23).

Segundo Sander (2009), nas décadas de 1960 e 1970, a gestão educacional se caracterizou por uma orientação centralizadora e homogeneizadora de gestão técnico-racional do estado planejador, preocupado com a economia, a produtividade e a eficiência. Essa orientação influenciou decisivamente os sistemas de organização e gestão da educação no Brasil. Foi assim que as perspectivas iniciais de gestão escolar deram origem a modelos dedutivos e práticas normativas, revelando uma preocupação prioritária com a manutenção e reprodução estrutural e cultural na organização escolar e na gestão político-institucional dos sistemas de ensino.

Observa-se, que a gestão educacional, ao longo dos anos, no sistema de ensino brasileiro passou por várias mudanças através de legislações, trazendo as especificidades de demandas de 
cada época. Nesta perspectiva histórica, em 1971, a legislação em vigor na época, previa um bloco único de escolarização básica obrigatória correspondente a oito anos (dos 7 aos 14 anos) e mais três anos de grau médio (15 aos 17 anos), denominamos, respectivamente, ensino de $1^{\circ}$ grau e ensino de $2^{\circ}$ grau.

Conforme descreve Sander (2009), no período de transição da década de 1970 para a década de 1980, culminou com uma efervescência política no Brasil, protagonizada pelos movimentos da sociedade civil organizada em favor da democratização, ações que se aprofundaram tiveram como resultado a promulgação da nova Carta Constitucional em 1988 (BRASIL, 1988).

No ano de 1988, a partir da promulgação da Constituição da República Federativa do Brasil, houveram mudanças na gestão educacional do país. Através da norma especificou-se, no Art. 205, no que tange a educação, que a mesma constitui-se como direito de todos e no Art. 211, instituiu-se a obrigatoriedade do regime de colaboração entre os sistemas de ensino. Esta foi uma mudança significativa, trazida pela norma, onde cada esfera, possui suas competências e deliberações próprias, nesta perspectiva de regime de colaboração. A redação, na íntegra, desses artigos, consta:

Art. 205. A educação, direito de todos e dever do Estado e da família, será promovida e incentivada com a colaboração da sociedade, visando ao pleno desenvolvimento da pessoa, seu preparo para o exercício da cidadania e sua qualificação para o trabalho.

Art. 211. A União, os Estados, o Distrito Federal e os Municípios organizarão em regime de colaboração seus sistemas de ensino (BRASIL, 1988).

Nos anos 1990 se estabelece, por parte do governo federal brasileiro, uma nova política educacional, definindo o ensino fundamental como o nível de ensino obrigatório e gratuito. Em 20 de dezembro de 1996, entra em vigor a lei 9.394, que estabelece as Diretrizes e Bases da Educação Nacional (LDB) (BRASIL, 1996).

Esta legislação regulamenta o sistema educacional público e privado a nível nacional e a forma de implementação dos mesmos. Reforça-se na referida legislação, uma gestão educacional baseada no regime de colaboração entre a União, Estados e Municípios no que se refere à promoção dos diferentes graus de escolaridade. E conforme discorre o parágrafo $1^{\circ}$, cabe à União a coordenação da política nacional da educação, conforme especificado, a seguir.

\footnotetext{
Art. $8^{\circ}$ A União, os Estados, o Distrito Federal e os Municípios organizarão, em regime de colaboração, os respectivos sistemas de ensino.

$\S 1^{\circ}$ Caberá à União a coordenação da política nacional de educação, articulando os diferentes níveis e sistemas e exercendo função normativa, redistributiva e supletiva em relação às demais instâncias educacionais (BRASIL, 1996).
}

Na perspectiva deliberada na nova LDB, o sistema educacional compõe-se da Educação Básica (formada pela Educação Infantil, Ensino Fundamental e Ensino Médio) e Educação Superior. No que tange à gestão e organização da Educação Básica no Brasil, cabe aos Estados, Distrito Federal e 
Municípios ofertá-las, sendo o Ensino Médio sob a competência dos Estados e a Educação Infantil sob a competência dos municípios.

Como estratégia organizacional impõe-se, assim, a gestão democrática, conceito consagrado na Constituição cidadã de 1988, na Lei de Diretrizes e Bases da Educação Nacional de 1996 e em instrumentos legais dos sistemas de ensino do país desta época e subsequentes.

Nos anos de 2001 a 2010, outra legislação importante, relativa à gestão educacional foi o Plano Nacional da Educação (PNE), com objetivo de proporcionar a melhoria da educação nacional com diversas metas. $\mathrm{O}$ documento, criado a cada dez anos, traça diretrizes e metas para a educação em nosso país, com o intuito de que estas sejam cumpridas até o fim desse prazo (BRASIL, 2001).

No que se refere ao Plano Nacional da Educação (PNE), um novo documento normativo foi redigido, que contempla os anos de 2011 a 2020. No documento, foi assegurado pelo governo, alinhar diretrizes e orientações as ações educacionais a âmbito federal (BRASIL, 2014).

Cabe destacar que as normas supracitadas, objetivam apenas explicitar que a organização da gestão educacional se dá através de normas reguladoras em nível de união, estados e municípios, sem o objetivo de aprofundar ou analisar o texto legal. Essas normas reguladoras é que balizam e orientam as ações da gestão escolar. Por meio destas diretrizes que é conduzido e articulado o direcionamento das ações de gestões escolares, sempre em consonância com a legislação nacional em vigor.

[...] a gestão educacional corresponde a área de atuação responsável por estabelecer o direcionamento e a mobilização capazes de sustentar e dinamizar o modo de ser e de fazer os sistemas de ensino e da escola, para realizar ações conjuntas, associadas e articuladas, visando o objetivo comum da qualidade do ensino e seus resultados (LUCK, 2006, p. 25).

Pode-se inferir, ante ao contexto exposto, que a gestão educacional é compreendida através das iniciativas desenvolvidas pelos sistemas de ensino. Já a gestão escolar, articula-se em consonância com a gestão educacional, mas desenvolve-se no âmbito escolar e trata das tarefas que estão sob sua responsabilidade, ou seja, promover o ensino e a aprendizagem.

\section{GESTÃO E ORGANIZAÇÃO ESCOLAR: CONTEXTO E DESAFIOS}

Considerando que a escola se constitui um importante espaço de formação e construção de conhecimentos, seu objetivo se cumpre pelas atividades pedagógicas, curriculares e docentes, viabilizadas pelas formas de organização e gestão.

A gestão escolar visa promover a organização, a mobilização e a gestão das condições físicas, humanas e materiais, para que cada estabelecimento de ensino possa colocar em prática a sua proposta pedagógica, promovendo a construção do conhecimento e a aprendizagem pelos alunos. Assenta-se, sobretudo, no elemento humano, no trabalho coletivo, no espírito de equipe, a fim de dar conta ao fim a que se propõe. 
[...] organização e gestão, em que organização é compreendida como unidade social que reúne pessoas que interagem entre si e que opera por meio de estruturas e processos organizativos próprios, para se alcançar os objetivos da instituição e gestão, o processo de tomada de decisões e a direção e controle dessas decisões. (LIBÂNEO, 2007, p. 157).

Entende-se que a escola necessita ser bem organizada e bem gerida para poder criar e assegurar condições organizacionais, operacionais, pedagógicas e didáticas para o bom desempenho de professores e alunos em sala de aula, de modo a promover um ensino de qualidade e o sucesso da aprendizagem. Para atingir seus objetivos, cada escola procura traçar seu percurso, sua trajetória a partir da orientação e direcionamento de ações a partir da sua gestão escolar, abarcando as diversas realidades e peculiaridade ((LIBÂNEO, 2018).

Por meio da gestão escolar, cada escola deve organizar-se para elaborar e executar sua proposta pedagógica, conduzir a administração de recursos pessoais e financeiros, atentar para sua proposta de ensino, assim como articular-se com as famílias e comunidade, proporcionando um contínuo processo de interação. [...] a gestão escolar organizada é necessária para que a escola possa ter estratégias e capacidade para trabalhar e superar as limitações (HENGEMÜHLE, 2004, p. 178).

Pode-se afirmar que uma escola bem organizada, no que se refere a gestão, é aquela que assegura meios operacionais e pedagógicas para o bom desempenho de professores e alunos em sala de aula, de modo a possibilitar sucesso na aprendizagem. Por conta disso,

A organização e gestão escolar diz respeito, usualmente, à estrutura de funcionamento, às formas de coordenação e gestão do trabalho, ao provimento e utilização de recursos materiais e financeiros, aos procedimentos administrativos etc., visando assegurar objetivos educacionais. Para além de uma visão administrativa, as organizações escolares têm sido abordadas como unidades sociais formadas de pessoas que atuam em torno de objetivos comuns, portanto, como lugares de relações interpessoais (LIBÂNEO, 2018, p. 269).

Neste sentido, é importante compreender a gestão escolar como uma atividade que integra de forma dinâmica diferentes elementos e setores da escola, através de ações sistemáticas e intencionais a fim de possibilitar a qualificação dos serviços educacionais prestados pela instituição.

[...] o ambiente escolar é considerado em sua dimensão educativa, ou seja, as formas de organização e gestão, o estilo das relações interpessoais, as rotinas administrativas, a organização do espaço físico, os processos de tomada de decisões, etc., são também práticas educativas. As escolas são tidas como instituições aprendentes, portanto, espaço de formação e aprendizagem, em que as pessoas aprendem com as organizações e as organizações aprendem com as pessoas. (LIBÂNEO, 2018, p. 270)

Um ponto importante a destacar no que diz respeito à gestão escolar, conforme a Lei de Diretrizes e Bases da Educação Nacional, LDB (1996), refere-se é a autonomia que a escola possui. Através desta autonomia prevista na norma, cada escola consegue adequar a sua proposta as especificidades locais e regionais, contemplando assim diferentes clientelas para o desenvolvimento de uma aprendizagem de qualidade (BRASIL, 1996). 
Conduzir um trabalho à frente da gestão escolar é uma tarefa desafiadora, seja no cargo que for, tanto na direção, vice direção, supervisão, coordenação pedagógica, orientação educacional, etc. Conduzir de forma adequada este complexo contexto demanda dedicação, conhecimento e persistência, para que se possa alcançar metas, cumprir o planejamento estratégico da instituição, e conduzir ações que possam viabilizar a condução do Projeto Político Pedagógico da escola. Além de acompanhar a prática docente, questões relacionadas ao desenvolvimento do ensino aprendizagem, novas metodologias, e toda a abrangência da relação família e escola.

Quanto ao Projeto Político Pedagógico, este se constitui é o eixo condutor da instituição escolar, é o documento que dá identidade ao trabalho desenvolvido pela instituição. É fundamental que a instituição escolar tenha esse documento construído coletivamente, e o papel da gestão na sua construção é fundamental, pois ele é a mola mestra propulsora da ação educativa da escola e a partir dele que a será colocada em prática. "O projeto pedagógico é, como demonstrado a pedra angular do fazer da escola. A partir dele, de outros documentos irão normatizar o cotidiano, como é o caso do regimento escolar, do plano global, plano de estudo e de trabalho [...] (HENGEMÜHLE, 2004, p. 179).

Entretanto, quando alunos e professores iniciam uma aula, em alguma escola, as condições do que se pode ensinar e aprender estão definidas pela interferência de instâncias que estão muito além do que se pode alcançar ao olhar. Por traz desta ação, observa-se um trabalho de uma equipe, através de uma gestão escolar articulada para que possa dar conta do fim a que a instituição se propõe que é a promoção do ensino, definido como:

O ensino, portanto, é uma atividade situada, ou seja, é uma prática social que se realiza num contexto de cultura, de relações e de conhecimento, historicamente construídas. Esse contexto se traduz em práticas socioculturais e institucionais - mais concretamente, as formas de organização, de gestão, de relacionamento, de tomadas de decisão, etc. - que jogam papel preponderante no desenvolvimento e aprendizagem dos alunos (LIBÂNEO, 2018, p. 275).

Assim sendo, o ensino e a ação educativa da escola são atividades situadas dentro de um determinado contexto e sujeitos, que se desenvolve através de normas e documentos previamente construídos coletivamente pela equipe e membros da gestão escolar e pelos profissionais que na instituição atuam.

Neste contexto, o gestor escolar, desempenha um papel importante que é o de mobilizar e orientar o trabalho de pessoas para desempenharem o melhor de si na realização do seu trabalho em diferentes áreas de atuação no ambiente da escola, tanto na área pedagógica, com vistas à promoção do ensino e aprendizagem, como na área operacional, procurando viabilizar meios para seu desenvolvimento.

O trabalho dos gestores escolares se assenta sobre sua capacidade de liderança, isto é, de influenciar a atuação de pessoas para o trabalho e aprendizagem e construção de conhecimentos, e tem em vista que a gestão se constitui em processo de mobilização e organização do talento humano para atuar de forma compartilhada na promoção dos objetivos educacionais (LUCK, 2014, p. 23). 
Entretanto, para conduzir este amplo contexto, intenção só não basta, é necessário orientar adequadamente, desenvolver um trabalho em equipe, aglutinando esforços coletivos, para a condução eficiente dos diversos e complexos setores que abrangem o ambiente escolar. Ao serem alçados ao desafio a maioria dos gestores contam com uma formação na área que o habilite a tal função, ou desenvolvam conhecimentos técnicos ou habilidades interpessoais que o possibilite desenvolver o seu trabalho. Conforme Luck (2014) liderança neste sentido, visa a promover esforços, voltados a uma equipe integrada, participativa e empreendedora na realização dos objetivos educacionais a que a escola se propõe.

Tendo como pressuposto que a escola é uma das mais importantes instâncias de democratização da sociedade e de promoção de inclusão social, cabe-lhe propiciar os meios de apropriação dos saberes sistematizados formados socialmente, como base para o desenvolvimento das capacidades intelectuais e a formação da personalidade por meio da atividade de aprendizagem socialmente mediada (LIBÂNEO, 2018, p. 12).

É essencial que os profissionais de educação que que atuam na gestão escolar tenham clareza do que significa o seu papel a fim de que possam nortear seu trabalho de forma conjunta e integrada, como também tenham conhecimentos dos processos da escola e do reflexo do seu trabalho sobre o seu cotidiano.

\section{CONCLUSÃO}

O estudo proposto procurou evidenciar a importância da gestão escolar para a escola, considerando os seus efeitos no direcionamento de ações para consolidar a proposta pedagógica de ensino, bem como considerar as práticas de organização e gestão para a melhoria de resultados institucionais.

Para alcançar o objetivo proposto, partiu-se de uma contextualização sobre a temática, a interrelação entre as políticas internacionais e a gestão educacional, articulando-as numa relação de interdependência que se observa ao longo dos anos. Nesse contexto, a gestão educacional diz respeito ao macro dos sistemas de ensino e possibilita ações estratégicas integradas, visando otimizar resultados na área da educação e no contexto da escola.

Assim sendo, verifica-se que para otimizar resultados e qualificar a proposta educacional da escola se faz necessário possuir uma gestão escolar organizada, a fim de criar e assegurar condições organizacionais, operacionais e pedagógicas para que possa viabilizar o bom desempenho do aluno, da prática pedagógica, a partir da mobilização e a articulação dos diferentes setores da escola.

Percebe-se que não é possível para escola atingir o fim a que se propõe e seus objetivos de melhoria do ensino e aprendizagem sem formas de organização e gestão. Necessita-se para tanto, uma gestão escolar que, através de sua equipe, contribua por meio de suas ações, tanto no sentido de provimento de meios para o funcionamento da escola como no sentido de melhoria de práticas institucionais formativas. 


\section{REFERÊNCIAS:}

AKKARI, A. Internacionalização das políticas educacionais: transformações e desafios. Petrópolis, RJ: Vozes, 2011.

BRASIL. Constituição. Constituição da República Federativa do Brasil. Organização Alexandre de Morais. 16. ed. São Paulo: Atlas, 2000.

BRASIL. Lei no 9.394, de 20 de dezembro de 1996. Estabelece as diretrizes e bases da educação nacional. Diário Oficial da União, Brasília, DF, 20 dez 1996. Disponível em: https://bit.ly/30YRgAa. Acesso em: 10 maio 2020.

BRASIL. Lei n. 10.172, de 9 de janeiro de 2001. Aprova o Plano Nacional de Educação e dá outras providências. Diário Oficial da União, Brasília, DF, 9 jan 2001. Disponível em: https://bit.ly/3s2Wffb. Acesso em: 10 maio 2020.

BRASIL. Lei n.13.005, de 25 de junho de 2014. Aprova o Plano Nacional de Educação e dá outras providências. Diário Oficial da União, Brasília, DF, 26 jun 2014. Disponível em: https://bit.ly/3sgnNOl. Acesso em: 10 maio 2020.

HENGEMÜHLE, A. Gestão de ensino e práticas pedagógicas. Petrópolis, RJ: Vozes, 2004

LIBÂNEO, J. C. Concepções e práticas e organização e gestão da escola: considerações introdutórias para um exame crítico da discussão atual no Brasil. Revista Española de Educación Comparada. Madrid, Espanha, n. 13., p. 155-191, 2007. Disponível em: https://bit.ly/2Nx5e9d. Acesso em: 27 abr. 2020.

LIBÂNEO, J. C. Organização e gestão da escola: teoria e prática. 6. ed. São Paulo: Heccus Editora, 2018.

LUCK, H. Concepções e processos democráticos da gestão educacional. 2. ed. Petrópolis, RJ: Vozes, 2006.

LUCK, H. Gestão educacional: uma questão paradigmática. 3. ed. Petrópolis, RJ: Vozes, 2007. 
LUCK, H. Liderança em gestão escolar. 9. ed. Petrópolis, RJ: Vozes, 2014.

SANDER, B. Gestão educacional, concepções em disputa. Revista Retratos da Escola, Brasília, v. 3, n. 4, p. 69-80, jan./jun. 2009. Disponível em: https://bit.ly/3cNrXqm. Acesso em: 5 maio 2020. 